Estudios sobre el Mensaje Periodístico

ISSN-e: 1988-2696

http://dx.doi.org/10.5209/ESMP.55586

\title{
Lo más leído: infoentretenimiento, propaganda y anécdotas en la versión digital de los diarios españoles
}

Coral Morera Hernández ${ }^{1}$

Recibido: 27 de mayo de 2016 / Aceptado: 7 de noviembre de 2016

Resumen. Este trabajo persigue demostrar que la prensa digital camina por la senda definida por la televisión. Desde finales de los ochenta, los asuntos mundiales han ocupado un lugar menor en la agenda informativa. Internet ha consolidado esta tendencia de tal forma que no es errado señalar que la prensa digital compite con la telerrealidad. Analizamos la sección de "lo más leído" de cinco diarios españoles: El País, El Mundo, ABC, Libertad Digital y El Confidencial en aras de determinar el componente de infoentretenimiento en un período de máximo interés, caracterizado por la desafección política, la apatía ciudadana y la desaparición del debate público.

Palabras clave: Prensa digital; infoentretenimiento; periodismo; sociedad de la información; lectores.

[en] Most read: Infotainment, propaganda and anecdotes in the digital version of Spanish newspapers

\begin{abstract}
This study tries to demonstrate that the daily digital press follow the path defined by television. Since the late eighties, world affairs have occupied a minor space on the news agenda. Internet has established this tendency so the digital press looks like very much to the reality television. We analyze the section "most read" in version digital of five Spanish newspapers: El País, El Mundo, $A B C$, Libertad Digital and El Confidencial in order to determine the increase of infotainment component in a period of maximum interest, characterized by political disaffection, citizen apathy and the disappearance of public debate.
\end{abstract}

Keywords: Daily digital press; infotainment; journalism; knowledge society; audience.

Sumario. 1. Introducción. 2. Metodología y justificación. 3. Corpus y análisis; 3.1 Análisis cuantitativo; 3.2 Análisis cualitativo. 4. Resultados. 5. Discusión. 6. Conclusión. 7. Referencias bibliográficas.

Cómo citar: Morera Hernández, Coral (2017): "Lo más leído: infoentretenimiento, propaganda y anécdotas en la versión digital de los diarios españoles", en Estudios sobre el Mensaje Periodístico 23 (1), 117-133.

\section{Introducción}

Los nuevos consumidores de información, que no lectores, son la "masa crítica" del nuevo escenario nacido en la sociedad de la información. El periodismo 2.0

1 Universidad de Valladolid.

E-mail: cmorera@hmca.uva.es 
ha alumbrado un ecosistema mediático que distrae y divierte al espectador desde plataformas caracterizadas por los pseudoacontecimientos. La inmediatez ha vencido al contenido; la cantidad a la calidad. Se trata, en su mayoría, _ como este estudio pretende avalar-, de noticias que juegan con las emociones, la curiosidad y el interés humano ${ }^{2}$. Son, en muchos casos, noticias sin trascendencia o descritas desde un ángulo extravagante. No parece que el objetivo sea informar, sino, en definitiva, crear cortinas de humo: cuanto más agitada es la actualidad, mayor es el triunfo de informaciones insustanciales y caducas ${ }^{3}$. Tal y como señala Eco en su última obra, "los periódicos no están hechos para difundir sino para encubrir noticias" (2015: 169) ${ }^{4}$.

Los diarios digitales parecen inmersos en el negocio de dotar de entidad a lo insignificante, Bourdieu lo llamó "fast food cultural” (1997: 40) y añadió que "los periodistas son peligrosos: como no siempre son muy cultos, se asombran de cosas que no tienen nada de extraordinario y permanecen indiferentes ante otras absolutamente portentosas" (Bourdieu, 1997: 63). Pero consideramos que no es la incultura de los periodistas de lo que se alimenta este "fast food", o no sólo, sino que es la propia supervivencia de lo digital lo que ha alumbrado este escenario periodístico tan anómalo. No obstante, periodistas y públicos, no son tanto responsables como víctimas de este ecosistema mediático. Hasta ahora, la verdad, o las buenas noticias, nunca eran noticia; la situación actual es peor: la nada triunfa como noticia.

Dos males aquejan a la prensa digital, y por ende, a sus públicos. Por un lado, convertir en noticias pseudoacontecimientos, o en su defecto, explotar una versión sensacionalista; y por otro, alimentar la aculturación de los lectores apelando a sus emociones. Las posibilidades mediáticas en la sociedad de la información están convirtiendo lo que hasta ahora había sido la lectura de prensa, en el consumo de titulares. "Son sociedades de riesgo" como explica (Farré, 2004), pero no sólo por la capacidad de provocar crisis como señala el autor, sino por la tendencia a empobrecer los contenidos. Señalaba Carr cómo se nos inculca que "navegar por la Red es un sustituto válido, incluso mejor, de la lectura profunda y otras formas de pensamiento calmado y atento" (2011: 140). Aunque tal y como sostiene el mismo autor, leer por la red es "como intentar leer un libro mientras resuelves un crucigrama: tal es el entorno intelectual de Internet" (155).

Los actuales diarios digitales están sistemáticamente demoliendo la cultura de los lectores. Neil Postman (1984) ya anticipó esa sociedad del espectáculo en la que sucumbíamos, mientras reflexionaba sobre el triunfo de las profecías de Orwell y Huxley. Unos años antes, Tuchman también señaló que una de las funciones de los medios era "transformar los acontecimientos en noticia" (1983: 180). Lo prioritario, parece, es crear contenidos que no provoquen rechazo. Las audiencias de prensa digital asisten a contenidos huecos y a menudo superficiales, cuando no sensacionalistas; algo que no había tenido cabida en la prensa española: un modelo de prensa di-

2 El tipo de periodismo que se denunciaba en "El gran carnaval", Billy Wilder (1951), la película de que peores críticas recibió este director por el retrato tan certero que hacía del comportamiento de la gente ante la desgracia ajena y la condena hacia el periodismo sensacionalista.

3 El escote de Susan Sarandon fue la noticia más leída en El País el 3 de febrero, 2016: "El escote de Susan Sarandon o el 'problema' de ser sexy a los 69 años en Hollywood".

4 Número cero es una sátira mordaz contra el periodismo y la instrumentalización de la información para extorsionar al poder. 
ferente, de élites, con un mayor nivel cultural ${ }^{5}$. Plataformas como Twitter están precipitando esta vorágine. Podríamos señalar que aquellas piezas que no se convierten en trending topic, que no son compartidas o muy comentadas, son informativamente, pobres, lo que no significa que no tengan interés. De hecho, que las noticias reciban muchas visitas no significa que sean las más interesantes ni las más importantes; no supone, ni siquiera, que sean interesantes. Tal extremo es el que este estudio persigue comprobar. Como advierte Baricco esta "civilización bárbara" sufre "de la facilidad, la superficialidad, los efectos especiales y la libido comercial" (2011: 167). Esa parece ser la evolución mediática. Sin embargo, no podemos, ni debemos, adoptar una actitud obtusa al respecto, sino dejar constancia de lo que está ocurriendo y abrir una línea de trabajo.

Desde hace algunos años, se ha venido investigando el infoentretenimiento en torno, fundamentalmente, a la televisión. Distintos estudios, nacionales e internacionales, han recogido la literatura al respecto: algunos de ellos (Brants, 1998; Berrocal et al. 2012; Prior, 2005, Negredo Bruna, 2015). Asimismo, se han llevado a cabo estudios sobre la participación del público a través de redes y comentarios de noticias (Mancera, 2009; Palau Sampio, 2012; Pastor, 2012, Perales García, 2014). Igualmente, el llamado "periodismo ciudadano" ha sido, y sigue siendo, objeto de interés por parte de algunos teóricos (Martínez Arias, 2015; Sorrentino, 2013, Salvat Martinrey et al. 2007). Pero no se ha llevado a cabo un análisis de las noticias más leídas en prensa digital en el período que nos ocupa, por lo que resulta estimulante como campo de trabajo y nuevas líneas de estudio y exploración.

Los lectores digitales superan a los de papel, sin embargo, ileen los usuarios digitales o simplemente navegan por un surtido número de titulares atrayentes y noticias anecdóticas o futbolísticas? Se preguntaba Bennett en 2002, cómo se podía evitar que el periodismo serio se convirtiera en "una boutique en la era de Internet" (Bennett, 2002: 265). Y el mismo autor defendía que era necesario "mezclar temas conocidos, artículos interactivos e imágenes"; "llenar las historias de luz y sonido" (ibídem). Es exactamente lo que ha ocurrido, aunque llamarlo periodismo serio se antoje una boutade. Muchos análisis académicos parecen embriagados por lo que la tecnología ha aportado a los medios de comunicación, sin tener en cuenta, por un lado, lo que se ha llevado por delante, y por otro, cómo internet ha revolucionado el periodismo creando consumidores de información pero no lectores. Se pregunta Di Pino (2011: web) sobre lo que denomina "un discurso huérfano de toda trascendencia”, si "¿hay diferencia entre un periódico que dice cosas que no se pueden leer y un periódico que no dice nada [...]?".

\section{Metodología y justificación}

Lo más importante de los medios de comunicación es el contenido. Los numerosos triunfalismos académicos sobre el valor de los nuevos medios de comunicación, está, de alguna manera, eclipsando los estudios que se atrevan a poner en duda dicho valor. A partir de esta hipótesis, este estudio persigue conocer las prácticas de consumo de prensa digital. Para ello hemos procedido al vaciado de prensa de noticias

Así se desprende del estudio, Hallin y Mancini (2004) 
en dos etapas: la primera abarca desde el 28 de julio hasta el 30 de octubre 2015; la segunda desde el 28 de diciembre 2015, hasta el 29 de febrero, 2016 ${ }^{6}$. Se recogen los datos de "lo más leído" en la edición de tarde de los diarios on line elegidos de lunes a viernes, excluyendo fines de semana y festivos. Consideramos que se trata de un período atractivo y estimulante. España atraviesa un interesante momento político, con la aparición de nuevas formaciones políticas y con una repercusión notable en las audiencias televisivas en formatos de variada índole. La política vuelve a estar "de moda", tras el hastío dejado durante la crisis económica, y sobre todo, "capta" al público joven que parecía haber permanecido en actitud tan distante como indiferente.

El hecho de pautar dos períodos de análisis nos parece interesante en aras de descubrir las rutinas de los lectores y detectar si hay o no coincidencia en el tipo de informaciones más leídas en función de distintos aspectos. Es decir, si el período estival, por ejemplo, es proclive a decantarse por un tipo de informaciones y cómo afecta a los públicos de cada uno de los medios. Por otra parte, se trata de un análisis inductivo que no plantea datos concretos a priori y que tiene carácter descriptivo. Hemos elegido cinco medios: la versión digital de tres rotativos influyentes: El País, El Mundo y $A B C$, y dos diarios exclusivamente digitales: Libertad Digital y El Confidencial. El estudio es de carácter cuantitativo y cualitativo con el propósito de ampliar los resultados y lo que ello supone como línea de investigación.

\section{Corpus y análisis}

\subsection{Análisis cuantitativo}

Las noticias que acaparan más visibilidad durante este primer período (28 de julio hasta el 30 de octubre 2015) son las siguientes:

- La cogida de Fran Rivera.

- La polémica sobre el Toro de la Vega.

- El arranque de la Liga de fútbol: fichajes.

- El escándalo de Volkswagen.

— La secesión de Cataluña.

- La vida en Marte.

- La crisis de Siria.

- Los asesinatos de Sergio Morate.

— El viaje de los Reyes a EE.UU.

\footnotetext{
6 No tenemos en cuenta diciembre por la campaña electoral, ni noviembre porque $A B C$ cambió de formato y eliminó durante un período de tiempo "lo más leído". Retomando la recogida de datos una vez se normaliza la situación.

7 La distinta denominación con la que cada diario se refiere al objeto de campo de nuestro estudio consta a continuación: El País: "Lo más visto". ABC: "Lo más leído"; El Mundo: "Lo más leído" y "Lo más visto". Libertad Digital: "Lo más leído", "Lo más oído", "Chic” y "Lo más comentado". El Confidencial: "Lo más leído" y "Lo más influyente".
} 
Tabla 1. Resultados cuantitativos primer período: julio-octubre 2015. Elaboración propia.

\begin{tabular}{|c|c|c|c|c|c|c|c|c|c|c|c|c|c|c|}
\hline & Anecdóticas & Deportes & Sucesos & Sociedad & Polít. Nacional & Internacional & Economía & Tecnología & Salud & TV & Taurinas & Viajes & Historia & Consumo \\
\hline \multicolumn{15}{|l|}{ 1ª Másleída } \\
\hline ElPaís & 8 & & 9 & 18 & 3 & 3 & 3 & & 2 & 1 & & & 1 & \\
\hline ElMundo & 7 & 2 & 12 & 13 & 10 & 3 & & & & & & & & \\
\hline$A B C$ & 6 & 5 & 7 & 12 & 5 & 1 & & 5 & 2 & & & 2 & 1 & \\
\hline Libertad Digital & & 13 & 2 & 1 & 29 & 1 & & & & & 1 & & & \\
\hline ElConfidencial & 8 & 1 & 4 & 6 & 22 & 2 & & 1 & 1 & & & 2 & & \\
\hline TOTALES & 29 & 21 & 34 & 50 & 69 & 10 & 3 & 6 & 5 & 1 & 1 & 4 & 2 & \\
\hline
\end{tabular}

Los listados de informaciones de actualidad no son coincidentes, ni en el primer ni en el segundo período, con las noticias más leídas en los diarios de nuestra muestra: los incluimos para dar cuenta de qué contenidos captaron la actualidad en ambos períodos con más intensidad, y cuáles fueron las preferencias de los lectores en función de dicha actualidad.

Tabla 2. Resultados cuantitativos segundo período: diciembre 2015-marzo 2016. Elaboración propia.

\begin{tabular}{|c|c|c|c|c|c|c|c|c|c|c|c|c|c|c|}
\hline & Anecdóticas & Deportes & Sucesos & Sociedad & Polít. Nacional & Internacional & Economía & Tecnología & Salud & TV & Taurinas & Viaies & Historia & Consumo \\
\hline \multicolumn{15}{|l|}{ 1a Más leída } \\
\hline El Pais & 1 & 2 & 9 & 16 & 6 & 1 & & & 2 & & & & & \\
\hline El Mundo & 1 & 1 & 11 & 3 & 15 & 1 & & & & & & & & 1 \\
\hline$A B C$ & 6 & 3 & 6 & 2 & 8 & & & 2 & 2 & & & 4 & 1 & \\
\hline Libertad Diqital & & 3 & & 2 & 29 & & 1 & & & & & & & 1 \\
\hline El Confidencial & & 4 & 3 & 7 & 18 & & 1 & 1 & 2 & & & & & 1 \\
\hline TOTALES & 8 & 13 & 29 & 30 & 76 & 2 & 2 & 3 & 6 & & & 4 & 1 & 3 \\
\hline
\end{tabular}

Las noticias que acaparan más atención durante este segundo período son las siguientes:

- La crisis de la Generalitat y la elección de nuevo presidente.

- La cabalgata de Reyes Mayos en Madrid.

- La muerte de David Bowie.

- Los pactos entre las fuerzas políticas tras las elecciones del 20D.

- El descubrimiento de las ondas gravitacionales.

- Casos de corrupción en el PP.

- La crisis de Vitaldent.

- El terremoto de Ceuta y Melilla.

- La detención del Chapo Guzmán.

- El asesinato de una niña al tirarla por una ventana.

- La crisis de la carne procesada.

- El juicio asesinato Isabel Carrasco.

- El inicio del juicio del caso Noos. 
Tabla 3. Resultados cuantitativos por diario, primer período. Elaboración propia.

\begin{tabular}{|l|l|l|l|}
\hline \multicolumn{1}{|c|}{ Medio } & \multicolumn{1}{|c|}{$\begin{array}{c}\text { Las primeras } \\
\text { más leídas }\end{array}$} & \multicolumn{1}{|c|}{$\begin{array}{c}\text { Las segundas } \\
\text { más leídas }\end{array}$} & \multicolumn{1}{|c|}{$\begin{array}{c}\text { Las terceras } \\
\text { más leídas }\end{array}$} \\
\hline El País & Sociedad: 18 & Sucesos: 9 & Anecdóticas: 8 \\
\hline El Mundo & Sociedad: 13 & Sucesos: 12 & Anecdóticas: 7 \\
\hline ABC & Sociedad: 12 & Sucesos: 7 & Anecdóticas: 6 \\
\hline Libertad Digital & Política nacional: 29 & Deportes: 13 & Sucesos: 2 \\
\hline El Confidencial & Política nacional: 22 & Anecdóticas: 8 & Sociedad: 6 \\
\hline
\end{tabular}

Tabla 4. Resultados cuantitativos por diario, segundo período. Elaboración propia.

\begin{tabular}{|l|l|l|l|}
\hline \multicolumn{1}{|c|}{ Medio } & \multicolumn{1}{|c|}{$\begin{array}{c}\text { Las primeras } \\
\text { más leídas }\end{array}$} & $\begin{array}{c}\text { Las segundas más } \\
\text { leídas }\end{array}$ & \multicolumn{1}{|c|}{$\begin{array}{c}\text { Las terceras } \\
\text { más leídas }\end{array}$} \\
\hline El País & Sociedad: 16 & Sucesos: 9 & Nacional: 6 \\
\hline El Mundo & Nacional: 15 & Sucesos: 11 & Sociedad: 3 \\
\hline ABC & Nacional: 8 & Sucesos: 6 & Anecdóticas: 6 \\
\hline Libertad Digital & Política nacional: 29 & Deportes: 3 & Sociedad: 2 \\
\hline El Confidencial & Política nacional: 18 & Sociedad: 7 & Deportes: 4 \\
\hline
\end{tabular}

Las tablas 3 y 4 denotan la uniformidad de sección de noticias más leídas en la versión digital de los tres diarios nacionales, e igualmente ocurre con los dos diarios digitales elegidos para la muestra. Si nos atenemos a la clasificación por diarios los resultados son los siguientes. El único medio que coincide en ambos períodos es Libertad Digital. En todos los demás se producen variaciones. Las coincidencias en los tres diarios nacionales en versión digital son muy evidentes en el primer período puesto que las noticias más leídas, Sociedad, Sucesos y Anecdóticas, coinciden. No así en el segundo período en cuanto a que en El Mundo y $A B C$ el primer puesto es para la información de política nacional, hecho que se explica por lo convulso del período y las elecciones generales. El País, por su parte, sigue manteniendo las noticias de Sociedad como las más leídas.

El porcentaje de noticias más leídas según los resultados cuantitativos sigue la siguiente trayectoria:

- Primer período: Nacionales, Sociedad, Sucesos, Anecdóticas y Deportes.

— Segundo período: Nacionales, Sociedad, Sucesos, Deportes y Anecdóticas.

Se observa la coincidencia de datos entre ambos períodos salvo el apartado de anecdóticas que es sensiblemente superior en el período estival y deportes, en el segundo, dado que comienzan los campeonatos deportivos, teniendo en cuenta que el fútbol absorbe toda la información deportiva.

La siguiente tabla resume los resultados totales y el orden de noticias más leídas según la sección. 
Tabla 5. Resultados cuantitativos totales ambos períodos. Elaboración propia.

\begin{tabular}{|c|c|}
\hline Sección más leída & Totales \\
\hline Política nacional & 145 \\
\hline Sociedad & 80 \\
\hline Sucesos & 63 \\
\hline Anecdóticas & 37 \\
\hline Deportes & 34 \\
\hline Salud & 11 \\
\hline Tecnología & 9 \\
\hline
\end{tabular}

\subsection{Análisis cualitativo}

Con respecto a un análisis cualitativo, hemos de revelar cómo una de las mayores dificultades del estudio ha residido en identificar la temática de la noticia por el titular. Es decir, nos hemos hallado en situaciones en las que el titular, mayormente sensacionalista, no aportaba datos sobre si se trataba de una noticia de sucesos, economía, deportes, salud, etc. Tal es el caso de las piezas que reproducimos a continuación y que fueron las más leídas:

— "De modelo a "mula", El Mundo, 9 de agosto, 2015.

— “Jägermeister: Historias para perder la memoria”, El País, 10 de agosto, 2015.

— “Los 7 muertos 'con perdón' de Risi”, El Mundo, 13 de septiembre, 2015.

— "Madera para evitar derroches", El País, 12 de octubre, 2015.

— "Pablo Planas: 'La puta traidora", Libertad Digital, 5 de enero, 2016.

— "La Nevera Roja: la muerte de un pelotazo", El Confidencial, 5 de febrero, 2016.

— "Elrubius: "Vivo a base de pedir comida por internet"", El Mundo, 8 de febrero, 2016.

— "Puñalada fatal al Pop de los 80", El Confidencial, 12 de febrero, 2016.

- "Jordi Evolé no encuentra lo que fue a buscar a Camboya", Libertad Digital, 23 y 24 de febrero, 2016.

Citamos a continuación aquellas piezas más leídas, consideradas sensacionalistas, extravagantes y con intencionalidad.

— "La mujer extraterrestre que la NASA ha filmado en Marte", $A B C, 12$ de agosto.

- "Un autobús lleno de presos tiene un accidente y en vez de huir, se dedican a ayudar", $A B C, 13$ de agosto.

- "Cinco curiosidades sobre Cleopatra que probablemente desconocías", $A B C, 18$ de agosto.

- "Los mejores memes sobre la expulsión de Piqué", $A B C, 19$ de agosto.

- "Esta es la verdadera razón por la que te huele el aliento", El Confidencial, 20 de agosto.

- "La isla habitada más remota del mundo busca profesores", $A B C, 15$ y 16 de septiembre, 2015.

- "Una denuncia de una felación "pistola en mano" complica el 'caso espías' en Madrid", El Confidencial, 15 de septiembre. 
- 'Los 'pijos' de Pozuelo ganan la primera batalla a McDonald's: paralizan las obras", El Confidencial, 23 de septiembre.

- "Las respuestas más brutas de las candidatas a reinas de la belleza", $A B C, 24$ y 25 de septiembre.

_ "Marisa Jara: 'He tenido que escuchar 'qué pena, con lo guapa que es y qué gorda está", El Mundo, 25 de septiembre.

- "El desmejorado aspecto de Johnny Deep", El País, 25 de septiembre.

- "Una profesora se desnuda ante sus alumnos", El Confidencial, 12 de octubre, 2015.

— "La transformación de Antonella Roccuzzo", El País, 13 de enero, 2016.

- "Lugares donde te puedes matar practicando deporte", $A B C, 2$ de febrero, 2016.

— "El Chapo a Kate del Castillo: "Te cuidaré más que a mis ojos"”, El País, 14 de enero.

— "Montezemolo: 'Tengo noticias de Schumacher y no son buenas"', El País, 5 de febrero.

- "El alcalde de Algaba: 'Se le dio — el contrato - porque me salió de la polla"', El Mundo, 23 de febrero, 2016.

- "El chascarrillo de Jordi Evolé sobre el Real Madrid que incomodó a Pilar Rubio", $A B C, 4$ de febrero, 2016.

- "El diputado de las rastas cobraba más de $50.000 €$ en una petrolera", Libertad Digital, 5 de febrero, 2016.

- 'Los votantes 'moderados' de Podemos 'pasmados' al descubrir que es chavista", Libertad Digital, 18 de febrero, 2016.

- "Anguita: 'Me gustaría volver un día al Congreso y decir: ¿ahora qué hijos de puta?"', Libertad Digital, 22 de febrero, 2016.

Exponemos a continuación aquellas piezas que fueron las noticias más vistas durante varios días consecutivos. Solamente dos noticias son las más vistas durante tres días seguidos. Son estas:

- "Diego, de 11 años, antes de suicidarse: "No aguanto ir al colegio", El Mundo, 20, 21 y 22 de enero, 2016.

- "Podemos plantea un histórico 'hachazo' fiscal a trabajadores, empresas, viviendas, etc", Libertad Digital, 15, 16 y 17 de febrero, 2016.

Las siguientes se repiten dos días consecutivos. Ordenadas cronológicamente se exponen a continuación:

- "Qué pasa si dejas el azúcar durante un mes", El País, 12 y 13 de octubre, 2015.

- "Los macropuentes que traerá 2016", ABC, 20 y 21 de octubre, 2015.

- "Blanca Padilla desvela la otra cara del mundo de la moda: vómitos, depresión y droga", $A B C, 22$ y 23 de octubre, 2015.

- "La OMS declara cancerígena la carne procesada", El País, 26 y 27 de octubre, 2015.

- "El padre de Marta del Castillo: 'Si me hubiera cargado a Miguel Carcaño, hoy yo estaría ya en la calle", El Mundo, 26 y 27 de octubre, 2015.

- "Justin Bieber: desplantes y despropósitos en su visita a España", El Mundo, 29 y 30 de octubre, 2015. 
- "Linchan a Antena 3 por denunciar la vinculación de Podemos, ETA, CUP y Venezuela", Libertad Digital, 21 y 22 de enero, 2016.

- "De qué equipo son los líderes políticos que quieren gobernar España", $A B C, 9$ y 10 de febrero, 2016.

- "Los peligros de tuitear contra Podemos", Libertad Digital, 11 y 12 de febrero, 2016.

- "Descubren las ondas gravitacionales", $A B C, 11$ y 12 de febrero, 2016.

- "Detenida la cúpula de Vitaldent por blanqueo y un fraude superior a los diez millones de euros a sus franquiciados", El Mundo, 16 y 17 de febrero, 2016.

- "Fallece a los 23 años Diego Carrasco: la gran promesa del Decathlon español", El Confidencial, 18 y 19 de febrero, 2016.

- "Jordi Evolé no encuentra lo que fue a buscar a Camboya", Libertad Digital, 23 y 24 de febrero, 2016.

- "Tira a una niña de 17 meses por la ventana tras ser sorprendido por la madre abusando de ella", $A B C, 26$ y 27 de enero, 2016.

Agrupamos a continuación aquellas informaciones en las que se produce una coincidencia de la misma noticia en tres diarios.

- La noticia del niño sirio muerto en una playa de Turquía, El Confidencial, El Mundo y El País, 4 de septiembre, 2015.

- El debate entre Albert Rivera y Pablo Iglesias en Salvados: Libertad Digital, El Confidencial y El Mundo, 19 de octubre, 2015.

- La Cabalgata de los Reyes Magos en Madrid, El País, El Mundo y ABC, 6 de enero, 2016.

- Terremoto en Ceuta y Melilla, El País, El Mundo y ABC, 25 de enero, 2016.

- Descubren las ondas gravitacionales, El País, El Mundo y ABC, 11 de febrero, 2016.

Nos ocupamos ahora de incluir noticias en las que coinciden dos diarios con la misma información:

- Pau Donés informa que tiene cáncer, El País y El Mundo, 2 de septiembre, 2015.

- La carne procesada, Libertad Digital y El País, 26 de octubre, 2015.

- Desplantes de la visita de Justin Bieber, El País y El Mundo, 29 de octubre, 2015.

- El no de la CUP, El País y El Mundo, 4 de enero, 2016.

- Muere David Bowie, El País y El Mundo, 11 de enero, 2016.

- Tira a una niña de 17 meses por la ventana, El Mundo y $A B C, 26$ de enero, 2016.

- Las declaraciones de Dani Rovira por la gala de los Goya, El País y El Mundo, 10 de febrero, 2016.

- Estafa de Vitaldent, El Mundo y $A B C, 17$ de febrero, 2016.

- Alejandro Sanz para un concierto, El País y $A B C, 22$ de febrero, 2016.

Exponemos a continuación el día de todo el análisis en el que todos los diarios coinciden en que la noticia más leída sea de política nacional excepto El Mundo. Se trata del 15 de febrero, 2016: 
- “Aguirre enseña el camino a Rajoy y dimite por la corrupción”, El País.

- "El PP retrocede doce escaños en un mes y Podemos adelanta al PSOE en votos", $A B C$.

- "Podemos lanza una propuesta humillante para el PSOE: quiere la vicepresidencia, el CIS, el CNI, el BOE...", Libertad Digital.

"Iglesias refuerza la repetición de elecciones con una contraoferta inasumible para Ferraz", El Confidencial.

- En El Mundo la noticia más leída es: “Arturo Pérez Reverte y Joaquín Sabina, a la sombra de un tequila".

Asimismo, incluimos las noticias del día 13 de enero, el día que se constituye el Parlamento catalán y las preferencias de los lectores.

— "La transformación de Antonella Roccuzzo", El País.

- "El holandés que ha puesto en jaque el sistema energético español", El Mundo.

- "Quince joyas del prerrománico asturiano", $A B C$.

— "Ada Colau se desdice del tuit a Bescansa", Libertad Digital.

— "Viaje a los orígenes de Carles Puigdemont", El Confidencial.

\section{Resultados}

La información digital ha convertido la prensa en un espacio para el "infoentretenimiento". Se trata de llegar al público, al mayor número de lectores, lo que algunos teóricos han denominado "economía de la atención" (Webster y Ksiazek, 2012: 41). Conseguir difusión parece el requisito primordial para el logro de objetivos económicos, sociales y políticos. No podríamos hablar de procesos de exclusión, dado que los diarios incluyen mucha información seria, - razón distinta es que se consuma o no-, sino de procesos de inclusión, en tanto incorporan noticias de forma intencional y que abarquen varias secciones o géneros noticiosos. De tal forma que Messi, no es noticia por ser uno de los mejores futbolistas del momento, o por ganar el Balón de Oro, sino que es su acompañante, Antonella Roccuzzo, el núcleo argumental del titular. Caso similar ocurre con la noticia sobre los comentarios de Jordi Evolé sobre el Real Madrid en un conocido programa de Antena 3, "El hormiguero". La noticia aquí es la reacción de la compañera sentimental de uno de los miembros del equipo madridista en el programa. Esta circunstancia de descontextualizar informaciones es algo común en la prensa digital.

Las versiones digitales de la prensa tienden a crear una agenda común. La visibilidad que ofrece la edición continua reduce al mínimo el tiempo de la novedad y conduce a sorprendentes semejanzas, tanto en los enunciados como en el desarrollo de la información, de medios que compiten entre sí. Parece ser que lo importante, según se desprende de los paralelismos de las agendas, consiste en no dejar de publicar cualquier información que publique el rival. (Díaz Nosty, 2011: 57).

Se observa la tendencia creciente de los diarios a disfrazar la información de diversión, morbo, es decir, apelar a aspectos primarios de lectores con pocas aspiraciones intelectuales. La información busca desplazar el mayor número de noticias a "Sociedad". Los diarios digitales se mimetizan con la televisión en una especie de reality. A este respecto, las noticias sobre programas televisivos son uno de los reclamos favoritos de 
los diarios objeto de análisis. En programas de aproximadamente dos horas de duración, a buen seguro, habrá alguna declaración que pueda convertirse en noticia e incluso que sirva de base ideológica. Es el caso de la siguiente noticia más leída: "Sara Carbonero: la última víctima del machismo de Bertín Osborne", El País, 25 de febrero, $2016^{8}$.

En nuestro análisis, tres programas televisivos: "Salvados" (La Sexta), "El hormiguero" (Antena 3) y "En tu casa o en la mía" (La 1), han obtenido noticias más vistas en nuestros diarios. Y no ofrecería datos conclusivos el hecho de obtener cobertura en la sección de televisión, sino que lo que lo hace excepcional, es precisamente que sea en piezas polémicas, descontextualizadas e incluso instrumentalizadas por cada diario. Nos hallamos ante noticias que invitan a la participación de los lectores, esa retroalimentación que tanto entusiasmo levanta en algunos sectores del mundo académico y que no es real. De los cinco diarios de análisis, solamente uno, Libertad Digital, permite la participación sin más filtro que el que Facebook aplique si algún comentario es objeto de denuncia. En los otros medios, la participación está sujeta a la moderación del propio medio y dicha moderación se encarga de no incluir aquellos comentarios que no coincidan con la postura del diario, aunque éstos se acojan a que incumplen las normas del debate ${ }^{9}$. Así las cosas, considerar a los receptores tan activos se nos antoja irreal y poco científico. El periodismo, efectivamente, se dota de una mayor transparencia porque los lectores pueden responder: matizar, corregir, ampliar, en definitiva, participar, pero la "censura" es mucho más sofisticada ahora.

La regla del entretenimiento ha pasado de centrarse en contar temas que son serios para los participantes y que provocan la curiosidad del lector a focalizarse en el enfrentamiento ideológico e, incluso, personal. El entretenimiento se vehicula a través del enfrentamiento de lectores, lo que provoca, sobre todo en la prensa digital española, la desaparición de la regla de la civilidad. En su lugar impera una nueva regla, la de la descortesía y la descalificación". (Pastor, 2012: 206).

Los usuarios consumen los productos "fabricados" por cada diario y eligen dentro de lo que el medio ofrece: un sinfín de noticias anecdóticas, irrelevantes, sacadas de contexto, o con un titular distorsionado que favorezca su difusión. Por otro lado, ese afán participativo, sobre todo en el caso español, es contraproducente, no ya porque no se complete la lectura de las informaciones, sino porque el nivel argumentativo de dicha participación deja mucho que desear y no aporta nada al debate. El trabajo de Pastor (2012), que compara el caso español con el de otros países occidentales, es muy ilustrativo a este respecto.

Los medios dan prioridad a la polémica frente al debate, la información, la reflexión o la dialéctica. Un hecho que en televisión se ha hecho norma, ha sido debidamente imitado en la prensa digital. Cuando la actualidad política es clave, como el momento que ocupa el presente análisis, la tendencia se intensifica, es decir, la audiencia desconecta de lo serio para engancharse a lo divertido: "La diversión tiende [...] a desviar la atención hacia un espectáculo cada vez que la vida política hace que surja una cuestión importante", (Bourdieu, 1997: 132). En el mismo sentido entendió Guy Debord (2007: 41) que el espectáculo "es el sol que nunca se pone en el imperio de la pasividad moderna".

Nos interesa incluir que en medio de la posible investidura de gobierno, pendiente de formar desde las elecciones del 20 de diciembre, 2015, y coincidente con el

\footnotetext{
8 Sorprende el enfoque que El País quiere dar a la información en una entrevista sustanciosa, tanto por el protagonista del programa en cuestión, Iker Casillas, como por conocer sus primeras palabras en una larga entrevista tras su polémica salida del equipo madrileño.

9 Sobre este particular se pronuncia el estudio de (Mancera Rueda, 2009).
} 
final del trabajo de campo, las opciones de los lectores sobre las cinco informaciones más vistas el 29 de febrero fueron estas:

\section{El País}

—Los ganadores de los Oscars 2016

- Vídeo: Así te hemos contado la gala de la $88^{\text {a }}$ edición de los Oscar

- AO VIVO | O Oscar 2016

-Vídeo: Halladas muertas dos senderistas perdidas por el temporal

—Vídeo: ¿Qué es un Año bisiesto y por qué existe?25 de febrero

\section{Libertad Digital}

— "Una mujer blande la cabeza decapitada de un niño al grito de 'Alá es grande' en Moscú"

— "El penúltimo raulista vivo: "Aquí huele a muerto"”

- "Jim Rogers: 'Esto va a ser un desastre, deberían estar muy preocupados"”

— "Federico Jiménez Losantos: “¿Qué le pasa a Rajoy con la Corona? "”

— "Adiós al mito de la isla de Pascua: su civilización no colapsó por la guerra ni la ecología".

$A B C$

— "Así se cebaron las redes con Cristiano, Zidane y el Real Madrid"

- "Si tienes alguno de estos móviles despídete de Whatsapp"

- "Diez maravillosas rutas en Andalucía sin tocar la playa"

— "Los científicos, desconcertados ante la misteriosa señal del Cúmulo de Perseo"

— "El hijo de Conde-Pumpido ha blanqueado 1,1 millones a una mafia de prostitución".

\section{El Mundo}

— "Horario y dónde ver la gala de los Premiso Oscar 2016"

- "Detenida en Moscú una mujer con la cabeza cortada de una niña en las manos y gritando "Alá es grande"”.

- "Hallan muertos a dos de los tres senderistas desaparecidos en el temporal de nieve de Castellón".

—_El paraíso antisistema de Ada Colau, la nueva Eva Perón"

— "La rebelión de los jóvenes del PP"

\section{El Confidencial}

— "Estafó ocho millones públicos y le pillaron por faltar al trabajo"

- "El despacho que quiere Monedero".

- "Detenida una mujer tras decapitar a una niña y pasear con su cabeza" Vídeo

- "Ganadores de los Premios Oscar 2016"

— "Florentino Pérez se plantea marcharse asolado por su errático modelo".

Hay una serie de contradicciones en nuestro trabajo de campo. Por ejemplo, no haber encontrado ninguna pieza más leída sobre el juicio Noos en ninguno de los diarios, tanto por la trascendencia como por las repercusiones, y que sin embargo, en un diario que no es monárquico, El País, la noticia más leída el 16 de septiem- 
bre sea: "La transformación de Letizia". Igualmente resulta llamativo encontrar tan elevado número de noticias más leídas de cierto matiz sensacionalista y de escasa trascendencia en $A B C$.

En nuestro estudio comprobamos que algunos diarios acusan una instrumentalización política mayor, como Libertad Digital, mientras El País absorbe la atención de sus lectores a través, fundamentalmente, de noticias de Sociedad. En $A B C$ el público persigue una variada mezcla de noticias anecdóticas, deportivas, de Historia o de prensa rosa. El Mundo, por su parte, lleva a cabo campañas a modo de "cruzadas". No es extraño, por ejemplo, que determinadas noticias sean las más leídas, habida cuenta del formato del diario y de la visibilidad que quiere dar a algunas de ellas. Es muy llamativo con el caso del niño que se suicidó por supuesto acoso escolar, noticia que aparece como más leída durante tres días consecutivos. A este respecto, el último cambio de formato del diario aplicado en noviembre de 2015, consolida esta tendencia. Es asimismo el diario que más utiliza citas textuales en los titulares. El sensacionalismo de El Mundo, no está orientado a temas de Sociedad, como ocurre con El País, o política nacional como sucede con Libertad Digital, sino con aquellas causas que el diario decida emprender. Con respecto a formatos, hemos de considerar que este aspecto también arroja contradicciones. El País es el diario más formal y de una mayor apariencia periodística; se observa una mayor coincidencia con una edición de papel. Las fotografías son pequeñas, es una página rápida, toda la información nacional ocupa un lugar prioritario y los temas menores, están al final de la página. Sin embargo, parece que los lectores de El País, sí se decantan por aquellas informaciones "blandas" o de Sociedad.

En $A B C$ no se observa tanto rigor en lo que a formato se refiere. Utiliza la columna izquierda para todos los temas políticos y más serios, pero equipara dichos temas con Corazón, deportes, etc, de tal manera que la importancia visual es similar. El Mundo tiene un formato muy llamativo, fotografias y titulares grandes, colores vistosos, y todo mezclado, es decir, el pacto entre PSOE y C's con lo que el diario llama "Destacados", donde puede figurar noticias del tipo: "la dieta de los actores de Hollywood" o "la mujer ya no quiere ser perfecta". Aquellas informaciones que el diario quiere enfatizar incluirán fotografías grandes. Parece que estamos haciendo un visionado de vídeos y fotos. Hay una ruptura de formato, no sólo con los otros dos diarios, sino con lo que es la versión de prensa en papel. En el caso de Libertad Digital hay cierta similitud con $A B C$, pero en su lugar, el diario digital incluye un espacio central para temas relacionados con Corazón y Deportes. El énfasis que este diario quiera hacer con determinadas informaciones, básicamente de política nacional, no vuelca, sin embargo, la atención de los lectores, dado que no ha coincidido en nuestro estudio el que noticias más destacadas visualmente hayan sido las más leídas. Convenimos en advertir que este hecho puede explicarse porque se trata del único diario que permite la participación en abierto, de ahí, esa ausencia de coincidencia entre lo destacado y las preferencias de los lectores. El hecho de poder incluir comentarios, facilita una mayor libertad para la audiencia, y ésta además, comprende un abanico ideológico mayor: ventaja que mantiene sobre los otros diarios de la muestra. La movilización de la opinión pública parece quedar garantizada por este motivo hacia noticias nacionales. Con respecto a El Confidencial, hay una similitud de formato con El Mundo, si bien, estamos ante una página muy lenta y bastante sensacionalista, con piezas morbosas que alcanzan toda la actualidad. Podemos advertir tras nuestro análisis, que es el diario que recurre a más titulares sensacionalistas, no en su versión de noticias sobre política nacional sino en lo referente a anecdóticas. 


\section{Discusión}

El nuevo periodismo 2.0 vaticinaba la fragmentación de la audiencia, con más posibilidades y recursos para tener un menú informativo a la carta. Jenkins advertía en 2008 que la innovación tecnológica facilitaba el empoderamiento del público. Sin embargo, esa abundancia informativa y tecnológica, no parece haber abundado en el poder ni en la calidad de los contenidos de los medios, ni por consiguiente, en el de sus públicos. No parece, en definitiva, que los contenidos de la prensa digital ayuden a los lectores a comprender el mundo en el que viven. Las razones pueden encontrarse en el ecosistema mediático al que asistimos donde los periodistas acercan un acontecimiento a la opinión pública de una manera muy concreta, y los medios de comunicación, como ya anticiparon autores de la Escuela de Frankfurt como Adorno y Horkheimer hace más de medio siglo (1944), se convierten en grandes creadores de ideología y sometimiento. Autores más recientes abundaron en la misma idea: "los medios de comunicación se han convertido en sistemas esenciales para la distribución de ideología" (Gitlin, 1980: 2).

La discusión que puede obtenerse aquí ahonda en la doble vertiente en la que cabe considerar al público de prensa digital. De un lado, la audiencia como responsable de los productos que consume, y de otro, si son los medios los que se desentienden ética y deontológicamente de los contenidos que incluyen. Todo hace pensar que las audiencias no utilizan la prensa digital para informarse sino más bien para desconectar de la información. Esto se intensifica cuando la actualidad nacional es crítica. No sería errado señalar cierto hartazgo en las audiencias, bien por una excesiva politización informativa, bien por una saturación de información. ¿La elección de los lectores refleja la demanda pública? No consideramos que el infoentretenimiento sea una demanda del público. Suele decirse, no sin cierto cinismo, que el mercado es sensible a las preferencias del público, sin embargo, éste es tan sólo una víctima de un panorama mediático extraño, extravagante y caracterizado por el entretenimiento; algo así como lo que Vidal Beneyto denominó la "hipertrofia informativa" que auguraba Internet (2002: 32). Es difícil, por no decir imposible, que la audiencia pueda mantenerse al margen de esta influencia. No podemos, por tanto, hacer al público responsable del consumo de determinados contenidos. El mercado, por imperiosa necesidad, ha sucumbido a sus objetivos empresariales sacrificando la calidad de las materias que incluye. Esa "existencia sostenible" a la que se refería Gustavo Bueno para la televisión (2003: 190), ha sido eficazmente asimilada por la prensa digital. Para que dicha existencia se sostenga, es necesario rellenar y actualizar contenidos que sean compartidos y que a su vez obtengan visitas y comentarios. Los actuales medios están subyugados a la viabilidad económica porque los modelos de negocio editorial on line, no son, per se, rentables. En un país como España, donde la lectura de prensa ha rondado de ordinario cifras paupérrimas, el modelo de diarios on line estaba destinado a triunfar y para ello tenía que alejarse de la prensa tradicional. Entendemos que hay una asimetría entre el valor de los contenidos y la producción de éstos. En pocas palabras, la información periodística tal y como la conocíamos ha perdido la razón de ser en su versión digital.

Estamos siendo hábilmente entrenados para prestar atención a banalidades. Un público amplio está dispuesto a conocer una actualidad que no le plantee reflexiones. Las preferencias de "lo más leído" en la prensa digital analizada, ofrece un curioso recorrido por la política, por la vida sentimental de los futbolistas o cualquier otra polémica 
en torno a éstos, por las noticias sobre Ciencia, Salud, así como sobre anécdotas de personajes famosos, que ni siquiera están relacionadas con su trayectoria profesional. Es tal el componente amarillista encontrado en algunas piezas que apenas si alcanza unos mínimos criterios periodísticos. Gran para de la literatura al respecto ha insistido en señalar que la Red es esa panacea que permite la democratización de la cultura y del saber, sin embargo, no parece que las elecciones de los lectores de prensa digital puedan probar tal extremo. Frente a los detractores del papel, y por ende, de la prensa, puede garantizarse que la calidad de ésta es superior con respecto a la digital. No es arriesgado señalar que los usuarios de prensa digital no son lectores, sino consumidores de titulares entretenidos. No obstante, no debemos alarmarnos por los resultados obtenidos sobre las noticias más leídas, en tanto en su conjunto se refieren a política nacional, lo cual es un dato optimista, si bien, el porcentaje relativo a Sociedad es llamativo, como también lo es el apartado de anecdóticas y deportes.

\section{Conclusión}

Este estudio parece concluir que la prensa digital permite navegar por titulares, más o menos atrayentes, pero no siempre de interés. La prensa digital, por su propio formato y por lo que exige su mantenimiento, no parece dejar otras opciones. No se puede equiparar leer una información en papel, con hacer click en un titular. La prensa digital se asemeja bastante a la información televisiva. No ya por la cantidad de vídeos que acompañan a las informaciones, — en el caso de El País—, muchas de las noticias más leídas son vídeos, sino por la estructura tan similar. La televisión da la misma importancia a la crisis de los refugiados que a los goles de los equipos más importantes de la liga. Es más, la información deportiva, junto con la meteorológica, han incrementado su importancia y duración de manera desproporcionada en muy poco tiempo. Si bien, los telenoticias televisivos relegan al final la información menor o de Sociedad, mientras en la prensa digital analizada, se incluyen un surtido de relatos que distraen y captan la atención al mismo nivel en toda la información del diario. Cuando los lectores se acercan a los diarios digitales eligen mayoritariamente piezas llamativas pero no siempre interesantes ni de actualidad. Los lectores de cada diario analizado parece que se decantan por las mismas secciones o noticias en los mismos diarios. La prensa digital analizada ofrece la apariencia de revista más que de periódico, lo que invita a concluir que los usuarios digitales se acercan a dicha prensa para echar una ojeada y pasar el rato, no para informarse. No parece que la popularización del periodismo digital esté significando un avance positivo. En la práctica, al llegar a más gente, se ha traducido en una mayor instrumentalización del público a través del entretenimiento como distracción.

\section{Referencias bibliográficas}

Adorno, Theodor y Horkheimer, Max (2001): Dialéctica de la ilustración: fragmentos filosóficos. Madrid, Trotta.

Baricco, Alessandro (2011): Los bárbaros: ensayo sobre la mutación, Barcelona, Anagrama.

Bennett, Lance (2002): La globalización, la desregulación de los mercados de los medios de comunicación y el futuro de la información pública. En: Vidal Beneyto, José: La ventana 
global: ciberespacio, esfera pública mundial y universo mediático. Madrid, Taurus, pp. 249-267.

Berrocal Gonzalo, Salomé; Redondo García, Marta; y Campos Domínguez, Eva (2012): "Una aproximación al estudio del infoentretenimiento en Internet: origen, desarrollo y perspectivas futuras". AdComunica. Revista Cientifica de Estrategias, Tendencias e Innovación en Comunicación, 4, 63-79. DOI: http://dx.doi.org/10.6035/21740992.2012.4.5

Bourdieu, Pierre (1997): Sobre la televisión. Barcelona, Anagrama.

Brants, Kees (1998): “Who's afraid of infotainment?”. European Journal of Communication, 13 (3), 315-335.

Bueno, Gustavo (2003): Telebasura y democracia. Madrid, Ediciones B.

Carr, Nicholas (2011): Superficiales: ¿qué está haciendo Internet con nuestras mentes? Madrid, Taurus.

Debord, Guy (2007): La sociedad del espectáculo. Madrid, Pre-Textos.

Díaz Nosty, Bernardo (2011): "La crisis en la industria de la prensa. Vida más allá del papel...". Telos: Cuadernos de comunicación e innovación, 86, 52-65.

Di Pino, Orlando Daniel (2011): “Avanza la tecnología, ique se salve el contenido!”. Cuadernos del Centro de Estudios en Diseño y Comunicación. Ensayos, 35: http://www. scielo.org.ar/scielo.php?script=sci_arttext\&pid=S1853-35232011000100005 [Consulta: 2 de febrero de 2016]

Eco, Umberto (2015): Número Cero. Barcelona, Lumen.

Farré Coma, Jordi (2004): "Espirales de riesgo en tiempos de crisis". Zer, Revista de Estudios de Comunicación, 17, 27-43.

Hallin, Daniel y Mancini, Paolo (2008): Sistemas mediáticos comparados: tres modelos de relación entre los medios de comunicación y la política. Barcelona, Hacer.

Gitlin, Todd (1980): The whole world is watching. Berkeley, University of California Press.

Jenkins, Henry (2008): Convergence culture: la cultura de la convergencia de los medios de comunicación. Barcelona, Paidós Ibérica.

Postman, Neil (2001): Divertirse hasta morir: el discurso público en la era del "show business". Barcelona, Ediciones de la Tempestad.

Tuchman, Gaye (1983): La producción de la noticia: estudio sobre la construcción de la realidad. Barcelona, Gustavo Gili.

Mancera Rueda, Ana (2009): "Manifestaciones de descortesía y violencia verbal en los foros de opinión digitales de los diarios españoles". Discurso \& Sociedad, 3 (3), 437-466.

Martínez Arias, Santiago (2015): "Periodismo ciudadano, en los límites de la profesión periodística”. Estudios sobre el Mensaje Periodístico, 21 (2), 109-118. http://dx.doi. org/10.5209/rev_ESMP.2015.v21.51132

Negredo Bruna, Samuel (2015): "Curiosidades y famosos en portadas digitales de noticias". Cuadernos de periodistas: revista de la Asociación de la Prensa de Madrid, 31, 18-29.

Palau Sampio, Dolors (2012): "Periodismo ciudadano en las ediciones digitales: una apuesta limitada", El profesional de la información, 21, 369-374.

Pastor Pérez, Lluís (2012): “Las nuevas reglas de la participación del público en la prensa digital. Análisis de siete diarios europeos de referencia". Estudios sobre el Mensaje Periodístico, 18 (1), 193-210. http://dx.doi.org/10.5209/rev_ESMP.2012. v18.n1.39365

Perales García, Cristina (2014): “Análisis de los comentarios de los usuarios en la prensa española en el debate de 'Ley Wert'". Historia y Comunicación Social, 19, 507-521. http://dx.doi.org/10.5209/rev_HICS.2014.v19.45045 
Prior, Markus (2005): "News vs. entertainment: How increasing media choice widens gaps in political knowledge and turnout". American Journal of Political Science, 49, 577-592.

Salvat Martinrey, Guiomar y Paniagua Santamaria, Pedro (2007): “¿Es esto periodismo, ciudadano?". Estudios sobre el Mensaje Periodístico, 13, 227-246.

Sorrentino, Carlo (2013): "El equívoco del periodismo ciudadano: cómo las nuevas formas de consumo de la información están redefiniendo el periodismo". AdComunica: revista cientifica de estrategias, tendencias e innovación en comunicación, 6, 21-37. http:// dx.doi.org/10.6035/2174-0992.2013.6.3

Vidal Beneyto, José (2002): "Introducción. Más allá de la comunicación”. En: Vidal Beneyto, José (coord.): La ventana global: ciberespacio, esfera pública mundial y universo mediático. Madrid, Taurus, 13-44.

Webster, James y Ksiazek, Thomas (2012): “The Dynamics of Audience Fragmentation: Public Attention in an Age of Digital Media". Journal of Communication, 62, 39-56. doi:10.1111/j.1460-2466.2011.01616.x

Coral Morera Hernández es Profesora doctora de "Teorías de la Comunicación y de la Información" del Departamento de Historia Moderna, Contemporánea, de América. Periodismo y Comunicación Audiovisual y Publicidad. Universidad de Valladolid, Campus "María Zambrano" Facultad de Ciencias Sociales, Jurídicas y de la Comunicación. 